\title{
Identidade e corporação médica no sul do Brasil na primeira metade do século $X X^{*}$
}

\section{Identity and medical corporation in the south of Brazil in the first half of the Twentieth century}

\author{
BEATRIZ TEIXEIRA WEBER \\ Departamento de História, Centro de Ciências Sociais e Humanas, \\ Prédio 74, Sala 210, Campus Universitário, Camobi, \\ Universidade Federal de Santa Maria (UFSM), 97105-900, Santa Maria, RS. \\ beatriztweber@gmail.com
}

\begin{abstract}
RESUMO Este texto analisa a organização da medicina no Rio Grande do Sul nas primeiras décadas do século XX, por meio da atuação dos médicos na Santa Casa de Misericórdia de Porto Alegre, na Faculdade de Medicina de Porto Alegre e no Sindicato Médico Rio-Grandense. A proposta dos médicos conflitou com a organização política positivista que possuía assento no governo gaúcho até 1928, procurando formas de inserção diversas, visando o fim da liberdade profissional no estado. Sua organização consolidou-se com o regulamento nacional para o exercício da medicina e das profissões correlatas em 1932, embora apresentando problemas para sua execução no Rio Grande do Sul. A efetiva delimitação das atividades ocorreu com a reorganização dos serviços de higiene e saúde pública,
\end{abstract}

* Artigo recebido em: 31/03/2010. Aprovado em: 4/08/2010. 
através do Regulamento do Departamento Estadual de Saúde do Estado do Rio Grande do Sul, de 1938, que determinou minuciosamente todos os encargos da assistência médica social.

Palavras-chave História da medicina, regulamentação profissional, identidade e corporação

ABSTRACT This text analyses the medical organization in Rio Grande do Sul state, in Brazil, through the doctor's performances at Santa Casa de Misericórdia in Porto Alegre city, at the Medicina Faculty and at the RioGrandense Medical Union. The doctors' proposal conflicted with the Positivist political organization which was part of the local government up to 1928, which aimed the end of the professional freedom in the state. The medical organization was consolidated with the national regulation for the medicine practice and correlated professions in 1932, although there was problems for its accomplishment in Rio Grande do Sul. The effective organization of the medical activity happened with the rearrangement of hygiene services and public health, through the Regulation of the State and Health Department of Rio Grande do Sul, in 1938, which determined in details all the duties of social medical care.

Keywords Medicine History, professional regulation, identity and corporation

\section{O contexto gaúcho e a prática médica}

No Brasil é grande a variedade das práticas de cura desde o período colonial. Os físicos eram bacharéis licenciados por universidades ibéricas; os doutores defendiam conclusões magnas ou teses em Coimbra, Montpellier e Edimburgo (principais universidades de medicina na Europa do século $\mathrm{XVI}$ ao XVIII); os barbeiros ou cirurgiões-barbeiros praticavam pequenas cirurgias, além de cortar cabelo e fazer a barba; os boticários comerciavam drogas e concorriam com os físicos e cirurgiões-barbeiros no tratamento das doenças. Havia, ainda, pessoas sem habilitação formal que receitavam e faziam curativos, de acordo com horizontes culturais diversos. Essas pessoas podiam ser curandeiros, pajés, benzedores, entre outras categorias. O objetivo deste texto é analisar a emergência da profissão médica num contexto específico, o Rio Grande do Sul na primeira metade do século XX, num espaço em que a assistência à saúde foi sendo gradativamente hegemonizada pela profissão médica, que buscou constituir-se formalmente como o único segmento legítimo da prática de cura. Esse grupo não possuía identidade como tal e procurou constituí-la ao longo do período, formando 
núcleo corporativo com interesses comuns através do Sindicato Médico do Rio Grande do Sul.

O material aqui apresentado representa releitura da temática a partir de novas contribuições existentes na historiografia gaúcha durante a década de 2000. Explicitamos o material produzido e incorporado posteriormente com o exato objetivo de destacar a nova historiografia que vem sendo realizada. Apesar de os elementos serem similares aos sugeridos pelo argumento produzido nos primeiros estudos, ${ }^{1}$ novas contribuições têm-se somado, especialmente pela reflexão de Felipe Almeida Vieira, ${ }^{2}$ autor que elaborou de forma muito amadurecida a organização dos médicos na região, através da análise da atuação do Sindicato Médico no Rio Grande do Sul no processo de regulamentação da medicina durante a década de 1930. Incorporo vários elementos propostos por ele, sobretudo a perspectiva do "fazer a classe", que deu origem ao título de seu trabalho, mostrando o argumento desenvolvido pelos médicos no período para a formação de identidade e memória desse grupo corporativo na região, através da regulamentação profissional. A atuação dos médicos que dirigiram o Sindicato e publicaram textos constituiu tentativa de definir uma classificação a respeito dos profissionais da cura, demarcando o segmento que se denomina "classe médica" e os diferenciando dos considerados "charlatões". Outros trabalhos tematizaram a medicina e outras práticas de cura, demonstrando como essa área de interesse tem crescido na pesquisa realizada no Rio Grande do Sul, assim como, aliás, no restante do Brasil nos últimos anos. ${ }^{3}$

1 WEBER, Beatriz Teixeira. As artes de curar: medicina, religião, magia e positivismo na República Rio-Grandense. Santa Maria/Bauru: EDUFSM/Edusc, 1999; WEBER, Beatriz Teixeira. Médicos e charlatanismo: uma história de profissionalização no Sul do Brasil. In SILVA, Mozart Linhares da. (org.) História, medicina e sociedade no Brasil. Santa Cruz: Edunisc, 2003, p.95-128

2 VIEIRA, Felipe Almeida. "Fazer a classe": identidade, representação e memória na luta do Sindicato Médico do Rio Grande do Sul pela regulamentação profissional (1931-1943). Porto Alegre: UFRGS, 2009. (História, Dissertação de mestrado).

3 WITTER, Nikelen Acosta. Dizem que foi feitiço: as práticas da cura no sul do Brasil (1845 a 1880). Porto Alegre: EDIPUCRS, 2001; WITTER, Nikelen Acosta. Males e epidemias: sofredores, governantes e curadores no sul do Brasil (Rio Grande do Sul, século XIX). Niterói: UFF, 2007. (História, Tese de doutorado); KUMMER, Lizete Oliveira. A medicina social e a liberdade profissional: os médicos gaúchos na Primeira República. Porto Alegre: UFRGS, 2002. (História, Dissertação de mestrado); SERRES, Juliane Conceição Primon. "Nós não caminhamos sós": o Hospital Colônia Itapuã e o combate à lepra no Rio Grande do Sul (1920-1950). São Leopoldo: Unisinos, 2004. (História, Dissertação de mestrado); SERRES, Juliane Conceição Primon. Memórias do isolamento: trajetórias marcadas pela experiência de vida no Hospital Colônia Itapuã. São Leopoldo: Unisinos, 2009. (História, Tese de doutorado); SILVEIRA, Éder. A cura da raça: eugenia e higienismo no discurso médico sul-rio-grandense. Passo Fundo: UPF, 2005; GILL, Lorena Almeida. Um mal do século: tuberculose, tuberculosos e políticas de saúde em Pelotas (RS) 1890-1930. Porto Alegre: PUC-RS, 2004. (História, Tese de doutorado); QUEVEDO, Everton Reis. "Isolamento, isolamento e ainda isolamento": o Hospital Colônia Itapuã e o Amparo Santa Cruz na profilaxia da lepra no Rio Grande do Sul (1920-1950). Porto Alegre: PUC-RS, 2005. (História, Dissertação de mestrado); SANTOS, Nádia Weber dos. Histórias de vidas ausentes: a tênue fronteira entre a saúde e a doença mental. Passo Fundo: UPF, 2005; KORNDORFER, Ana Paula. "É melhor prevenir do que curar": a higiene e a saúde nas escolas públicas gaúchas (1893-1928). São Leopoldo: Unisinos, 2007. (História, Dissertação de mestrado); LORENZO, Ricardo de. "E aqui enloqueceo": a alienação mental na Porto Alegre escravista, c. 1843-c. 1872. Porto Alegre: UFRGS, 2007. (História, Dissertação de mestrado); TOMASCHEWSKI, Cláudia. Caridade e filantropia na distribuição da assistência: a Irmandade da Santa Casa de Misericórdia de Pelotas - RS (1847-1922). Porto Alegre: PUC-RS, 2007. (História, Dissertação de mestrado); SCHWARTSMANN, Leonor Baptista. Olhares do médico-viajante Giovanni Palombini no Rio Grande do Sul (1901-1914). Porto Alegre: EDIPUCRS, 2008. Para indicar o amplo crescimento da produção 
O processo de regulamentação da profissão é luta por definição de identidade em que agentes e grupos interessados em impor seu ponto de vista atuam através de entidades que então negociam e pressionam as autoridades visando atender às demandas. Nesse sentido, as definições teóricas de Pierre Bourdieu foram muito bem empregadas por Felipe Vieira para definir as disputas em torno das "identidades regionais", como a luta por classificações ou pelo monopólio de impor a definição legítima das divisões do mundo social e, assim, fazer e desfazer os grupos, no caso, da corporação médica, invocando algum tipo de "autoridade" dessa definição para a "instituição". Esses grupos constituíram um "sistema simbólico" que os referenciasse e desse identidade, não sendo só um reflexo da posição social. Os sistemas simbólicos são parte das ações dos grupos, objetos de suas disputas e elementos de dominação de um sobre outros, cada grupo dispondo de forças e recursos que dependem das posições relativas que ocupam em diferentes espaços da vida social. ${ }^{4} \mathrm{O}$ "poder simbólico" precisa ser evidenciado nas situações em que menos se deixe ver ou até seja invisível, exercido com a cumplicidade daqueles que não querem saber que a ele estão sujeitos ou que o exercem. ${ }^{5}$

A problemática de como os médicos definem sua própria categoria e sobre sua identidade profissional foi tratada também por Lizete Oliveira Kummer, ${ }^{6}$ analisando textos produzidos pelos médicos na Faculdade de Medicina de Porto Alegre desde 1915, na Revista dos Cursos, e na Sociedade de Medicina de Porto Alegre, através da revista Archivos Rio Grandenses de Medicina, que começou a ser publicada em 1920. Importante destacar que esses conjuntos documentais, não acessíveis até bem pouco tempo atrás, vêm sendo disponibilizados para consulta de pesquisadores interessados. Essa produção intelectual foi uma estratégia de afirmação profissional, de defesa corporativa de uma "medicina social", reunindo os esforços dos médicos gaúchos pelo reconhecimento legal da profissão e pelo monopólio nas artes de curar.

Para se ter uma ideia do panorama em que se inseriam os médicos no final do século XIX, Porto Alegre, capital do Estado do Rio Grande do Sul, possuía cerca de 52.000 habitantes e 37 médicos em 1890. Além desses profissionais, diversos outros práticos exerciam as artes de cura e, até que os médicos conseguissem algum poder de influência, tiveram que manter luta feroz contra os demais práticos. ${ }^{7}$

no Brasil, as edições da revista História, Ciências e Saúde - Manguinhos, mantida pela Casa de Oswaldo Cruz (Fiocruz) constituem excelente indicativo dos trabalhos que estão sendo produzidos no Brasil.

4 VIEIRA, Felipe Almeida. "Fazer a classe", p.23-24.

5 BOURDIEU, Pierre. O poder simbólico. Rio de Janeiro: Bertrand Brasil, 2009, p.7-8.

6 KUMMER, Lizete Oliveira. A medicina social e a liberdade profissional.

7 WEBER, Beatriz Teixeira. As artes de curar. Os trechos a seguir pertencem a essa obra. 
Um dos grupos com grande entrosamento na população era o das parteiras, que atendiam às "moléstias de senhoras" em geral e realizavam partos, como também conviviam cotidianamente com as mulheres, em relação muito próxima. Explicavam as dificuldades e os desconfortos, utilizando perspectivas reconhecíveis por todas. Os "incômodos no útero" tratados pelas parteiras podiam significar desde as mais diversas doenças venéreas até inflamações sem diagnóstico preciso (do útero, do ovário, etc.), tratadas com lavagens de água fervida e líquidos "perfumosos", tampões de tecido introduzidos no útero (curativos), "sublimados corrosivos", etc. O maior "incômodo", entretanto, era a gravidez não desejada, e várias parteiras provocavam abortos. Compartilhavam, portanto, a intimidade feminina, partilhando suas dificuldades, sendo companheiras e confidentes, e, por isso, mais aceitas do que os médicos no atendimento de seus problemas.

Não por acaso a primeira medida dos médicos foi um curso de partos na Santa Casa de Misericórdia de Porto Alegre, em 1897, visando ter algum controle sobre a atividade dessas curadoras. A partir desse curso, médicos formados na Faculdade do Rio de Janeiro e que atuavam no Rio Grande do Sul organizaram um curso de medicina com o objetivo de formar profissionais no Sul do Brasil. Esse foi o terceiro curso de medicina organizado no país, depois da Faculdade de Medicina da Bahia, em Salvador, fundada quando da passagem da família real rumo ao Rio de Janeiro, em 1808, e da Faculdade de Medicina do Rio de Janeiro - ambas criadas para implantar uma sistemática mínima de saúde na antiga colônia. A Faculdade de Medicina do Rio de Janeiro exerceu o planejamento sobre a situação da organização sanitária no país durante todo o século XIX.

Também não foi por acaso que os médicos organizaram suas atividades iniciais na Santa Casa de Misericórdia de Porto Alegre, um dos principais locais de práticas de cura do Rio Grande do Sul no princípio do século XX e uma das poucas instituições de atendimento aos pobres. O crescimento e transformação do perfil da Santa Casa nas décadas iniciais do século XX acompanhou o próprio desenvolvimento e as alterações urbanas de Porto Alegre, aprofundando os significados sociais e culturais da misericórdia, que era basicamente de recolhimento, passando aos poucos a assumir o papel da terapêutica. Nesse contexto, os médicos passaram a ter papel mais expressivo. A utilização do hospital como escola para preparação dos alunos da Faculdade de Medicina fez com que novas tecnologias fossem sendo adotadas e que a pesquisa se tornasse elemento de modificação das condições do hospital. Essa situação só foi de fato viabilizada após os médicos terem assumido a administração, a partir de 1915, consolidando-se finalmente em 1919, com o Regulamento do Serviço Sanitário do Hospital, que refez a organização da instituição sob novos padrões de higiene e novas orientações de funcionamento, com base no conhecimento técnico da medicina preocupada com o tratamento das enfermidades. A medicina 
ocupava espaço institucional para assumir novas funções sociais, em contexto no qual disputava espaço político para a efetivação de sua proposta de grupo frente à liberdade profissional. ${ }^{8}$

A organização republicana ocorreu com a implantação de uma proposta positivista no Rio Grande do Sul, especialmente após a adoção da Constituição estadual de 1892, em que Júlio de Castilhos garantiu esses princípios, inspirado em ideais do Apostolado (organização de indivíduos que professavam o positivismo, doutrina defendida por Augusto Comte. Apesar de boa parte desses princípios não ter sido mantida na prática, o de liberdade profissional e religiosa foi assegurado. A Constituição garantia que qualquer pessoa pudesse exercer uma profissão, sem privilégios de nenhuma formação específica, assim como garantia a liberdade religiosa e de cultos no estado. Segundo esse ideário, cabia à população decidir que propostas the pareciam mais adequadas para adoção, tanto na escolha profissional em geral como na opção religiosa.

A lei, portanto, assegurava que qualquer pessoa pudesse exercer a medicina, bastando que se inscrevesse na Diretoria de Higiene e pagasse as taxas devidas ao governo. Essa situação permitiu que práticos em geral exercessem a cura legalmente, até se nomeando médicos, só não podendo usar o título de doutor. Havia diversos curadores atuando, como "cartomantes-médicos", "médicos de senhoras", benzedores, espíritas, curandeiros. Durante a década de 1920, Porto Alegre chegou a ser denominada "uma cidade do outro mundo" devido à quantidade e diversidade de práticas exercidas, especialmente práticas místicas e esotéricas.

Nesse contexto, a preocupação dos médicos em pressionar para exigir a regulamentação da profissão manifestou-se constantemente. A atuação dos médicos da Faculdade de Medicina de Porto Alegre, responsável por dar uma formação técnica para os novos profissionais, foi um dos principais elementos de pressão sobre o governo estadual.

Cabe lembrar que essa situação era frontalmente diferente da perspectiva que triunfou no nível nacional. Embora não fosse clara a orientação federal, já que a norma que se incorporou ao texto da Constituição Federal de 1891 foi a garantia do livre exercício de qualquer profissão moral, intelectual e industrial, o decreto de 1890, instituindo o Código Penal, introduziu três artigos referentes à prática ilegal da medicina e da magia, e à proibição do curandeirismo. No Rio de Janeiro, a proibição da liberdade profissional e a atividade das associações religiosas foram amplamente regulamentadas e fiscalizadas, havendo, aliás, um tribunal especial para os artigos citados do Código Penal até o início do século, o Juízo dos Feitos da Saúde Pública.

8 WEBER, Beatriz Teixeira. As artes de curar; FRANCO, Sérgio da Costa e STIGGER, Ivo. Santa Casa 200 anos: caridade e ciência. Porto Alegre: Ed. da ISCMPA, 2003. 
Na Faculdade de Medicina de Porto Alegre alguns episódios expressaram as divergências entre a posição dos médicos e do governo estadual. Um deles, de 1906, teve início em função da reprovação da tese final de um dos alunos da faculdade, o que levou vários estudantes às ruas, questionando a decisão da comissão examinadora. Suspensos por indisciplina, eles instituíram um processo contra a punição, que foi decidido por órgãos do governo federal, em última instância. A intervenção federal sobre um órgão estadual, que reivindicava autonomia, gerou o pedido de demissão coletiva dos professores da faculdade partidários do governo positivista. Alegavam ser inadmissível que o governo federal interviesse no estado, pois defendiam total independência dos órgãos de ensino, com base no princípio geral de não intervenção sobre as profissões e o ensino.

Essa debandada da faculdade gerou inúmeros problemas, apesar de alguns professores terem permanecido em suas funções. A faculdade deu continuidade a suas atividades, ainda que sofrendo com a falta de apoio do governo estadual, que já não era muito. O governo chegou a estimular a organização de outra faculdade de medicina, fundada em 1915, a Escola Médico-Cirúrgica de Porto Alegre, que manteria a total liberdade de ensino e aceitou a matrícula dos alunos da Faculdade de Medicina Homeopática, fundada em 1914. O fato de a Escola Médico-Cirúrgica não estar referida nas várias publicações que os médicos organizaram sobre a história da medicina no estado sugere, claramente, que ela concentrou os interesses do estado na manutenção do princípio de liberdade profissional, não tendo o respaldo dos demais médicos formados.

Essa disputa durou até o final do governo de Borges de Medeiros, em 1928, tendo havido apenas um interregno nas divergências, quando um médico formado, Carlos Barbosa Gonçalves, assumiu o governo do estado, de 1908 a 1913. Graduado no Rio de Janeiro, esse presidente facilitou as relações com a direção da Faculdade de Medicina de Porto Alegre, amparou financeiramente a entidade e doou, junto com a Intendência Municipal, um terreno no Campo da Redenção para que fosse construído o novo prédio da faculdade. Apesar de positivista, Carlos Barbosa tratou de resguardar os interesses dos médicos, enquanto grupo profissional, por meio da faculdade.

Os médicos de formação institucional não defendiam irrestritamente o ideário positivista. Protásio Antônio Alves - médico ativo que participou da fundação da faculdade, foi secretário dos Negócios do Interior e Exterior, diretor da Higiene e chegou até a assumir a Presidência do estado, em 1919, substituindo Borges de Medeiros -, apesar de suas convicções públicas, era a favor da vacinação; os positivistas eram contrários. Quando ocorria alguma epidemia, sua intervenção baseava-se nos princípios da medicina de seu tempo: notificação à Diretoria de Higiene, desinfecção das residências e isolamento dos doentes. Esses princípios contrariavam o ideário defendido 
pelos seguidores locais de Augusto Comte, defensores da possibilidade de cada indivíduo escolher os procedimentos que achasse mais adequados para tratamento dos problemas de saúde de sua família. Segundo esses princípios, o desenvolvimento e a divulgação da ciência garantiriam que essas pessoas fossem informadas e pudessem escolher os procedimentos mais avançados. Jamais poderiam ser obrigados a adotar qualquer medida contrária a suas crenças. Alguns positivistas, aliás, também participaram da Revolta da Vacina, no Rio de Janeiro, em 1904, porque eram contrários à obrigatoriedade da vacinação.

\section{A regulamentação profissional}

Em resumo, a questão da liberdade profissional foi motivo de conflito e hostilidade dos médicos ao Partido Republicano Rio-Grandense - PRR, facção política dos positivistas no estado. Outros médicos que também exerciam cargos no partido hostilizaram a questão, como os delegados de higiene das cidades de Alegrete, São Sebastião do Caí e Itaqui, e alguns episódios reforçaram essas divergências. Em 1926, Porto Alegre sediou o 9o Congresso Médico Brasileiro, que tentou pressionar em favor da regulamentação profissional. Durante a leitura de tese defendendo a regulamentação, houve a intervenção de tropas policiais no recinto, cerceando a manifestação de princípios contrários à Constituição estadual. A disputa manteve-se acirrada. Só houve outra perspectiva no estado após Getúlio Vargas assumir o governo, em 1928.

Felipe Vieira aponta que as primeiras críticas mais contundentes à liberdade profissional foram elaboradas pela Sociedade de Medicina de Porto Alegre, na tentativa de elevar a condição dos médicos diplomados. ${ }^{9} \mathrm{~A}$ entidade foi fundada em 1908, com o fim de tratar dos interesses do grupo sob os pontos de vista científico, moral e profissional. Apesar de várias dificuldades em sua manutenção, publicou a revista Archivos Rio-grandenses de Medicina desde 1920, com interregno entre 1923 e 1926. Os artigos e editoriais da revista indicam maior envolvimento dos médicos com questões sociais, segundo Lizete Kummer, incluindo temas como proteção à infância e maternidade, vinculada às doenças venéreas, sexualidade e família; uso de álcool e entorpecentes; saúde pública e organização dos serviços sanitários. Destacam-se a ideia de desenvolvimento de consciência sanitária na população e a defesa do fim da liberdade profissional. ${ }^{10}$

Desde 1916, a Sociedade de Medicina de Porto Alegre havia planejado a realização do primeiro congresso médico no estado, no qual a liberdade profissional seria um dos temas. O governo do estado, entretanto, proibiu

9 VIEIRA, Felipe Almeida. "Fazer a classe", p.44.

10 KUMMER, Lizete Oliveira. A medicina social e a liberdade profissional, p.74. 
a inscrição dos médicos funcionários públicos, e a comissão organizadora desistiu de realizar o congresso. ${ }^{11}$ Só em 1926 Porto Alegre veio a sediar o congresso, já então em sua nona edição, que apontou a necessidade de organização do grupo profissional através da proposta do ensino de ética entre os médicos. Um estatuto seria responsável por determinar a seleção das capacidades e a moralização da profissão, cerceando o charlatão e protegendo o médico consciencioso. Propunha um Conselho Nacional de Medicina, com sede no Rio de Janeiro, ligado ao Departamento de Saúde Pública, e conselhos estaduais. Acrescentava um Código de Deontologia, estabelecendo os deveres pessoais do médico, bem como os relativos a colegas, clientes e coletividades. Felipe Vieira aponta outros pontos de disputa sobre a liberdade profissional que surgiram a partir dos textos e moções apresentadas no congresso e que se mantiveram destacados nos artigos da revista da Sociedade de Medicina. ${ }^{12}$

Outras tentativas de organização profissional ocorreram. Em 1928, no 1 - Congresso Municipal de Saúde Pública, Medicina Social e Hospitais em Rio Grande ${ }^{13}$ foi apresentada tese lançando a ideia de um sindicato médico rio-grandense, já sugerindo proposta de estruturação. O Sindicato Médico Brasileiro foi fundado em 1927, objetivando "promover a defesa e o amparo da classe, manter estreita solidariedade entre seus membros e ditar-lhes regras de conduta profissional nas relações entre eles, entre o médico e o cliente e entre o médico e as coletividades". ${ }^{14}$ Os principais interesses do sindicato seriam a organização de um código de deontologia médica e ética profissional, a melhoria da situação econômica da "classe", o combate ao charlatanismo, ao curandeirismo e à prática desonesta da medicina, o estreitamento das relações sociais entre os membros, a regulação do processo de habilitação do profissional estrangeiro, as questões referentes ao ensino médico, a criação da "casa do médico", a promulgação de lei que regulasse as questões concernentes aos riscos e acidentes profissionais, e o amparo jurídico do grupo.

Deve-se acrescentar que no Rio Grande do Sul, a atuação dos médicos durante a organização do sindicato já visava ao fim da liberdade profissional, solicitando ao diretor-geral da Saúde Pública decreto que regulamentasse a profissão e sugerindo ao governo provisório a necessidade de extinguir a interpretação de liberdade profissional. ${ }^{15}$ Ocorriam divisões na Socieda-

\footnotetext{
11 KUMMER, Lizete Oliveira. A medicina social e a liberdade profissional, p.75.

12 VIEIRA, Felipe Almeida. "Fazer a classe", p. 46-51.

13 VIEIRA, Felipe Almeida. "Fazer a classe", p. 48.

14 Porto Alegre. Arquivo da Faculdade de Medicina da Universidade Federal do Rio Grande do Sul. (AFAMED) Syndicato Medico Brasileiro. Como ficaram organizados os seus Estatutos approvados em Assembléa Geral de 9 de Dezembro de 1927. Supplemento da Medicamenta. Revista Scientifica de Terapeutica e Pharmacologia, p.67, jan 1928. A documentação do referido arquivo está organizada em caixas, sem mais referências, só constando o que está citado.

15 AFAMED. T. M. A liberdade de profissão e a ação do Sindicato. Boletim do Sindicato Medico do Rio Grande do Sul, Porto Alegre, ano 1, n.4, p.10, out-dez 1931.
} 
de de Medicina e na Faculdade de Medicina, e não havia consenso entre os médicos rio-grandenses sobre a liberdade profissional. As disputas extrapolavam o âmbito da medicina e envolviam rixas de cunho políticopartidário ou mesmo pessoais, não havendo uma situação simplista que definisse os lados de forma categórica. A ascensão de Getúlio Vargas ao governo estadual em 1928, contudo, foi indicativa de que a questão da regulamentação profissional poderia ser solucionada. Também foi nesse período que as lideranças dos partidos políticos rio-grandenses procuraram superar suas discordâncias históricas para a formação da Frente Única no estado. Felipe Vieira analisou essa conjuntura e concluiu que as discussões e a linguagem empregada no campo político também foram apropriadas pelos médicos em seus anseios de terem atendidas suas reivindicações corporativas, demonstrando que essa questão dependia também da intervenção estatal. ${ }^{16}$

A fundação do Sindicato Médico Brasileiro, em 1927, fez parte de conjuntura em que os médicos gaúchos também se inspiraram. Alguns outros sindicatos setoriais, como de produtores de charque e arroz, também foram criados nesse momento no Rio Grande do Sul. A preocupação com a defesa dos interesses corporativos, visando à associação das classes para a participação política já se fazia presente no Brasil, e o grupo que ascendeu ao poder com a Revolução de 1930 também procurou implementar projeto do tipo "corporativista", sobretudo através da "lei de sindicalização", criada em 1931. Ainda que essa normativa não tenha sido determinante para a criação do Sindicato Médico, porque sua primeira versão só previa associações de empregados ou patronais, o Sindicato Médico do Rio Grande do Sul foi reconhecido pelo Ministério do Trabalho em 1936, depois da reforma da lei a partir da Constituição de 1934, que incluiu a sindicalização dos profissionais liberais. ${ }^{17}$

A fundação do Sindicato Médico Rio-Grandense, em 1931, teve como função explícita a regulamentação da liberdade profissional, apresentando contra os charlatões vocabulário que nunca havia sido tão impiedoso. $\mathrm{O}$ primeiro número do boletim do sindicato foi basicamente dedicado à discordância da liberdade profissional. O sindicato foi responsável por pressões ao governo federal e, após 1930, ao governo provisório, para que fosse regulamentado o exercício da medicina e profissões correlatas, o que se concretizou pelo decreto 20.931, de 11 de janeiro de 1932. O sindicato tinha por missão unificar a "classe" médica, segundo os termos usados na época, superando as divergências, e representar seus "interesses", fazendoos ouvidos no campo político. O sindicato teria caráter diferente do papel da Sociedade de Medicina, "estritamente científica", devendo ser o órgão

16 VIEIRA, Felipe Almeida. "Fazer a classe", p.51-53.

17 Aponto aqui a discussão exaustivamente realizada por VIEIRA, Felipe Almeida. "Fazer a classe", p.57-60. 
permanente de "representação" da totalidade da "classe", com atuação voltada para a esfera política, e promover a unidade da "corporação". Esses elementos poderiam garantir a eficácia do sindicato, o que não ocorrera em tentativas anteriores por intermédio da Sociedade de Medicina. ${ }^{18}$

O decreto regulava e fiscalizava o exercício da medicina, da odontologia, da medicina veterinária, dos farmacêuticos, das parteiras e dos enfermeiros, só permitindo o exercício em qualquer parte do território nacional a quem se achasse habilitado de acordo com as leis federais e tivesse seu diploma registrado no Departamento Nacional de Saúde Pública e na repartição sanitária estadual competente. Os médicos e cirurgiões-dentistas tinham ainda que notificar à autoridade sanitária ou policial a sede de seus consultórios ou residências; essa medida produzia no primeiro semestre de cada ano um cadastro médico e odontológico. ${ }^{19}$

Apesar do interesse e da necessidade geral do decreto, sua aplicação passou por diversos problemas no Rio Grande do Sul. O Sindicato Médico do Rio Grande do Sul solicitou, em diversas ocasiões, que o decreto fosse efetivamente aplicado, porque ele estaria sendo retardado, mantendo-se, mediante apoio de alguns políticos, na "licenciosidade profissional" existente. Sem qualquer tipo de registro profissional, os médicos tiveram que registrar de seus diplomas, e seus colegas do interior tiveram dificuldade para cumprir essa determinação, tendo o prazo para tanto sido prorrogado até 31 de janeiro de 1933, com o apoio do sindicato. ${ }^{20}$

Nesse contexto de rearranjos, algumas situações não foram aceitas prontamente. Duas delas foram alvo de controvérsias. A primeira refere-se ao registro dos médicos estrangeiros. No Rio Grande do Sul, alguns deles contrataram advogado para preservar o direito de exercício profissional sem o registro de diploma, ${ }^{21}$ gerando debate que se estendeu até o final dos anos 30, quando perderam judicialmente o direito de exercer a profissão, sendo então obrigados a se submeter à revalidação do diploma.

A segunda controvérsia refere-se ao fechamento da Escola MédicoCirúrgica de Porto Alegre, em 1931, por não ter sido considerada idônea para continuar a exercer a formação profissional. Após várias tratativas, foi feito acordo para transformação da escola em Faculdade de Farmácia, Odontologia e Obstetrícia, podendo ser ampliada para formar enfermeiros e padioleiros - não seria mais um curso de medicina. Os alunos matricu-

18 VIEIRA, Felipe Almeida. "Fazer a classe", p.61 e 63.

19 AFAMED. Rio Grande do Sul. Decreto n.20.931 de 11 de janeiro de 1932. Syndicato dos Profissionaes Formados pela "Escola Medico-Cirurgica" de Porto Alegre. Porto Alegre: Typ. Gaucha, 1932, p.5-6.

20 AFAMED. Documento 113. Datilografado. Sem título. Trata-se de relatório sobre a situação, provavelmente realizado pelos membros do Sindicato.

21 Uma nota no jornal Correio da Manhã de 25 de janeiro de 1933 afirmava que os médicos sem diploma haviam fundado um sindicato pleiteando a manutenção da liberdade profissional. AFAMED. Documento 112. 
lados seriam transferidos para escolas de medicina reconhecidas, mas os diplomas emitidos até aquela data seriam considerados. ${ }^{22}$

Até o momento não foram encontradas referências ao andamento da escola após esse acordo. A Escola Médico-Cirúrgica ainda tentou novo reconhecimento oficial em 1938, mas o parecer da Comissão de Ensino Superior negou-o, argumentando uma série de irregularidades: insuficiências financeiras, inexistência de local para a prática dos alunos, precárias condições de infraestrutura, etc. ${ }^{23}$ Esta última tentativa parece ter encerrado a trajetória da escola, como tanto queriam os médicos da Faculdade de Medicina de Porto Alegre.

Nesse contexto de controvérsias, todas as tentativas de denunciar os "charlatões" e de conquistar espaços para os médicos com diplomas oficialmente reconhecidos só conseguiram efetivar-se após a reorganização dos serviços de higiene e saúde pública no estado, em 1938. Minucioso regulamento do Departamento Estadual de Saúde passou a concentrar todos os encargos dos serviços de higiene e assistência médico-social de finalidade sanitária de todos os municípios do estado. Justificava-se a normativa argumentando-se que a maioria dos municípios não dispunha de aparelhamento nem de recursos financeiros e técnicos para manter repartições sanitárias e que havia aspiração a programa uniforme sem prejuízo das atividades regionais especiais. Também se afirmava que era precária a situação do estado quanto às políticas de saneamento, de combate à tuberculose, lepra, tracoma, mortalidade infantil e doenças transmissíveis agudas, o que evidenciaria "a necessidade de não retardar o seu aparelhamento de defesa da raça". ${ }^{24} \mathrm{O}$ regulamento estabelecia também que haveria uma divisão administrativa e uma divisão técnica, que incluiriam os setores de Fiscalização do Exercício Profissional, Bioestatística e Epidemiologia, além das seções de Educação e Propaganda, Higiene Escolar, Fiscalização de Gêneros Alimentícios, de Leite e Laticínios e de Profilaxia da Raiva.

A fiscalização do exercício profissional recebeu minuciosa regulamentação, só permitindo o exercício da medicina, "em qualquer dos seus ramos e sob qualquer de suas formas, a quem se mostrar habilitado por título conferido por escola oficial, federal ou equiparada na forma da lei". ${ }^{25}$ Obrigava os médicos ao registro do diploma na Seção de Fiscalização Profissional do Departamento Nacional de Saúde e no Departamento Estadual de Saúde e ao uso de carteira de identidade profissional fornecida pela repartição competente, além da notificação da sede de seus consultórios

22 AFAMED. Documento 117. Xerox de recorte de jornal, não identificado nem datado, provavelmente de maio de 1932. "A Gréve da Escola Medico Cirurgica. Foi Soluccionada pelo governo do Estado".

23 AFAMED. Documento 115. Datilografado. Comissão de Ensino Superior. Parecer 376.

24 AFAMED. Rio Grande do Sul. Regulamento do Departamento Estadual de Saúde do Estado do Rio Grande do Sul a que se refere o Decreto n. 7.481 de 14 de setembro de 1938. Porto Alegre: Of. Gráf. da Livraria do Globo, 1939, p.5.

25 AFAMED. Rio Grande do Sul. Regulamento do Departamento Estadual de Saúde, p.143. 
e suas transferências em cadastro médico, que serviria para considerar as reclamações feitas às autoridades.
Atentava para o exercício de outras práticas:
Art. 505 - Todo aquele que, mediante anúncio ou outro qualquer meio, se propuser ao exercício da medicina, sem título devidamente registado [sic], fica sujeito às penalidades aplicáveis ao exercício ilegal da medicina.
Parágrafo 1ํ- Nenhuma associação religiosa ou de propaganda doutrinária poderá dar consultas médicas ou praticar atos inerentes ao exercício da medi- cina, fornecendo ou não medicamentos a doentes, sem que nela haja serviço médico-farmacêutico regularmente instalado, ficando sujeitas, nas pessoas de seus diretores ou responsáveis, às multas estabelecidas para o exercício ilegal da medicina e às penas previstas na consolidação das leis penais e demais leis aplicáveis.
Parágrafo $2^{\circ}$ - A autoridade sanitária recorrerá às autoridades competentes para determinar o fechamento destas associações no caso de reincidirem na infração do exercício ilegal da medicina. ${ }^{26}$

Essa proibição atingia todos os centros de atendimento que funcionavam no estado, permitindo fechá-los ou criando-lhes problemas. Determinava que o exercício de práticas de cura fosse exclusivo de médicos oficialmente regulamentados. Qualquer erro ou falta grave seria punido com suspensão do exercício profissional, além da penalidade criminal a que incorresse. Destacava os deveres do médico, incluindo obedecer aos princípios de deontologia, escrever receitas por extenso, legíveis, em português, a tinta, indicando o nome do medicamento e o nome e endereço do paciente; observar disposições sobre receituários de entorpecentes e sobre doenças de notificação compulsória; atestar óbitos de acordo com a Nomenclatura Internacional de Causas de Morte e Doenças; mencionar apenas os títulos científicos e a especialidade nos anúncios.

O regulamento fazia diversas proibições. Os médicos diplomados não poderiam ter consultórios comuns com quem exercesse ilegalmente a medicina, não deveriam assumir a responsabilidade ou auxiliar o tratamento médico realizado por quem não estivesse legalmente habilitado; não podiam ter consultório em qualquer compartimento dependente de farmácia, laboratório farmacêutico, drogaria, ervanaria ou casa de óptica, não sendo permitido sua instalação em lugar cujo acesso se fizesse pelo recinto privativo de tais estabelecimentos; não poderiam manter consultório por correspondência através da imprensa, só se permitindo a divulgação de conselhos de higiene e assuntos gerais de medicina ou de ordem doutrinária, sem caráter de terapêutica individual, nos jornais leigos. Procurava atentar a todos os aspectos passíveis de regulamentação, tentando não 
deixar brechas de nenhuma espécie. O regulamento abordava também os estabelecimentos dirigidos por médicos, a prescrição de entorpecentes, as perícias médicas dentro da regulamentação da medicina. Outro capítulo tratava da profissão farmacêutica e da fiscalização de produtos que interessassem à medicina e à saúde pública, prescrevendo detalhadamente os procedimentos. ${ }^{27}$ Além da medicina, outras profissões tornaram-se alvo da legislação: ortopedistas, ópticos práticos, enfermeiros, parteiras, massagistas, manicures e congêneres, exigindo algum tipo de habilitação para sua prática - ou formação ou exame de habilitação. ${ }^{28}$ Fica evidente que tudo parece ter sido regulamentado.

A organização foi considerada modelar pelos médicos, refazendo, a partir daí, a luta contra o charlatanismo no Rio Grande do Sul e a aplicação do decreto que regulamentava a profissão médica. Essas medidas indicam maior presença de interesses médicos procurando regular o universo da prática profissional. Trata-se de longo processo de disputas que não se extinguiu após a publicação das leis, mas que representou uma vitória formal dos médicos. No Rio Grande do Sul, só após essas regulamentações é que os médicos passaram a ter algum "poder". A construção desse poder, entretanto, também passou por estratégias de convencimento da população e de formulação das versões sobre os acontecimentos que circulam até hoje.

Com todas essas mudanças em andamento, os médicos procuraram consolidar suas visões numa publicação que afirmava o que tinha sido a história da medicina no Rio Grande do Sul. A publicação do Panteão Médico Riograndense, ${ }^{29}$ em 1943, parece "fundar" a visão sobre a medicina no estado. Tendo analisado o Panteão Felipe Vieira conclui que a obra pode ser entendida como operação de "formalização da memória" de um grupo particular. Nesse empreendimento foram envolvidos os atos, conscientes ou não, de lembrar, comemorar, esquecer e silenciar através dos quais os grupos e indivíduos conectam seu passado à imagem que forjaram de si mesmos. ${ }^{30}$ Significativamente, o médico-chefe da fiscalização do exercício profissional do Departamento Estadual de Saúde afirmava, em texto publicado no Panteão, que inúmeros "charlatões" no interior haviam sido localizados e desalojados, que se retiraram do estado ou mudaram de profissão, com a colaboração do Sindicato Médico e da Repartição Central de Polícia. Também estariam realizando intensa propaganda educativa, prevenindo a população. Com essas medidas, juntamente com o levantamento do nível dos estudos médicos, a limitação das matrículas nas escolas de

27 AFAMED. Rio Grande do Sul. Regulamento do Departamento Estadual de Saúde, p.145-168.

28 AFAMED. Rio Grande do Sul. Regulamento do Departamento Estadual de Saúde, p.169-173.

29 FRANCO, Álvaro, RAMOS, Sinhorinha Maria. Panteão Médico Riograndense: síntese cultural e histórica. Progresso e Evolução da Medicina no Estado do Rio Grande do Sul. São Paulo: Ramos, Franco Editores. 1943.

30 Vieira, Felipe Almeida. "Fazer a classe", p.176. 
medicina, a sindicalização obrigatória e a criação da ordem dos médicos " limparemos para sempre o Rio Grande da pecha de ter sido a Meca dos curandeiros e charlatões". ${ }^{31}$

Estava, enfim, definitivamente extinta a liberdade profissional. E, finalmente, proclamava-se a visão oficial da medicina como a conhecemos hoje, eliminando as versões das demais práticas de cura que disputaram essa contenda.

31 ARAÚJO, José Barros de. O combate ao charlatanismo no Rio Grande do Sul. In: FRANCO, Álvaro, RAMOS, Sinhorinha Maria. Panteão Médico Riograndense, p.57. 